\title{
Effect of Scapular Retraction Exercise on Shoulder Alignment, Pulmonary Function and Aerobic Capacity in Subjects with Forward Shoulder Posture
}

Reethu Elsa ${ }^{* 1}$, Jesmi John. A ${ }^{2}$, Mohammed Shafeeq K P ${ }^{3}$, Sivani. U.A ${ }^{4}$, Remya. N $^{5}$, Manju Unnikrishnan ${ }^{6}$.

${ }^{*}$ Assistant Professor, Department Of Physiotherapy, Little Flower Institute of Medical Science and Research Centre, Angamaly, Kerala, India.

2,3,4 Student, Department Of Physiotherapy, Little Flower Institute of Medical Science and Research Centre, Angamaly, Kerala, India.

5,6 Professor, Department Of Physiotherapy, Little Flower Institute of Medical Science and Research Centre, Angamaly, Kerala, India.

\section{ABSTRACT}

Background: Forward shoulder posture is identified when the acromion process is most anteriorly positioned when compared with the position of mastoid process, which is characterized by acromion protraction infront of the line of gravity as well as protraction, downward rotation and anterior tilt of scapula. It is one of the common postural abnormality that accounts for $60 \%$ of shoulder abnormalities, with an incidence of $75 \%$ in the right side and $66 \%$ in left side. The study aims to find the effect of scapular retraction exercises on shoulder alignment, pulmonary function and aerobic capacity in subjects with forward shoulder posture.

Methods: The study was conducted on 14 subjects with FSP within the age group of 18 to 25 . Scapular retraction exercises were given to the subjects for a duration of 3 weeks. Pre and post test values of scapular index, chest expansion, incentive spirometry and six minute walk test was taken.

Results: Subjects showed statistically significant differences with a mean difference of $0.7(\mathrm{~cm})$ for scapular index right, $0.68(\mathrm{~cm})$ for scapular index left, $0.59(\mathrm{~cm})$ for upper chest expansion, 1.21(secs) for inspiratory hold time using incentive spirometry and $6.79(\mathrm{~m})$ for aerobic capacity $(\mathrm{p}<0.05, \mathrm{Cl}=95 \%)$. Pre and post mean scores of scapular index, chest expansion, inspiratory hold time and 6 minute walk test reveals that scapular retraction exercises has a positive impact on improving shoulder alignment, pulmonary function, and aerobic capacity

Conclusion: Scapular retraction exercises is effective in improving shoulder alignment, pulmonary function and aerobic capacity in subjects with Forward shoulder posture

KEY WORDS: Forward shoulder posture, rounded shoulder, pulmonary function, aerobic capacity, scapular retraction exercises, lung volume.

Address for correspondence: Reethu Elsa, Assistant Professor, Little Flower Institute of Medical Sciences and Research, Ernakulam, Kerala, India. E-Mail: reethuelsa@yahoo.com

Quick Response code

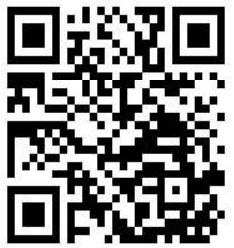

DOI: $10.16965 /$ ijpr.2021.154

$\mid$

Peer Review: 12 Jun 2021

Revised: None
International Journal of Physiotherapy and Research

ISSN (E) 2321-1822 | ISSN (P) 2321-8975

https://www.ijmhr.org/ijpr.html

DOI-Prefix: https://dx.doi.org/10.16965/ijpr

\section{Article Information}

Accepted: 13 Jul 2021

Published (O): 11 Aug 2021

Published (P): 11 Aug 2021

\section{INTRODUCTION}

Forward shoulder posture (FSP), also called as rounded shoulder, refers to a posture charac- terized by acromion protraction infront of the line of gravity due to protraction, downward rotation as well as anterior tilt of scapula [1]. 
Forward shoulder posture (FSP) is identified when the acromion process is most anteriorly positioned with comparison to the mastoid process, when observed in lateral view [2]. FSP is one of the common postural abnormality that accounts for $60 \%$ of shoulder abnormalities. Its incidence has been reported as $75 \%$ in the right side and $66 \%$ in left side [3].

FSP can be caused due to various day to day activities like repetitive overhead movements, backpack carriage, mouth breathing, use of computer, laptop or mobile phones and prolonged study hours. It could be attributed that, presence of excessive and habitual flexion of the back eventually causes the pectoral muscle to shorten and fix shoulder in this forward position [4].

In a forward shoulder posture, anterior muscles like Pectoralis Major and Minor, Upper Trapezius, Serratus Anterior, and Intercostals become tight due to being in a shortened state, while the posterior shoulder muscles such as Middle and Lower Trapezius, Rhomboids and Rotator cuff muscles becomes lengthened and weak [5].

It is seen that FSP may affect the pulmonary function with a distinct decrease in respiratory values such as FEV1, FVC and FEV1/FVC, which is caused due to various mechanisms. Shortening of accessory muscles of respiration such as Serratus Anterior, Intercostal muscle, Pectoralis Minor in FSP may increase energy expenditure and reduce respiratory values. FSP also decreases the expansion of lungs during inspiration and reduce compliance of respiratory system [6-8].

Maximal breathing capacity in patients causes voluntary forcing of respiratory efforts and exosorbant energy expenditure for the respiratory muscle performance, which becomes a leading factor of reduced aerobic working capacity [9].

Scapular retraction exercises are a set of exercises that helps to strengthen the scapular retractors like middle Trapezius and Rhomboids. It also helps to pull the scapula back into proper position which will in turn improve the shoulder alignment and FSP.

The present study aims to find the effect of scapular retraction exercise on improving shoulder alignment, pulmonary function, and aerobic capacity in subjects with FSP.

\section{METHODS}

The present pre-test, post-test single group experimental study was conducted on 27 subjects who fulfilled the inclusion criteria. Ethical approval was obtained from institutional ethical committee and all subjects gave their written informed consent. The included subjects within the age group of 18 to 25 , with a scapular index value of $2.6 \mathrm{~cm}$ or more were recruited from the physiotherapy college where the study was performed.

The study included both males and females with a BMI between 18 and 24.9. All subjects with respiratory problems or breathing difficulties, cardiac problems, recent surgery, fracture, degenerative or inflammatory conditions of spine \& shoulder, spinal deformities, chest wall deformities, shoulder deformities other than FSP, history of neck pain, and shoulder pain were excluded. Informed consent was taken from all the subjects. Name, age, gender, weight, height, $\mathrm{BMI}$ of each subject was recorded before the study.

Shoulder alignment was measured using scapular index which is measured distance between posterior acromion process and surface. Pulmonary function was assessed using Incentive spirometry and measurement of chest expansion. Aerobic capacity was measured using 6MWT. Pre-test scores of scapular index, chest expansion, incentive spirometry and 6MWT were taken.

Subjects were given scapular retraction exercise for 3 weeks. There are five sets of exercises which included Standing chest stretch, Camel stretch, Scapular band flye, Scapular wall hold and Peanut thoracic extension. Each exercise was done for 15 times per day. They were allowed rest breaks whenever required. The exercises were continued up to 3 weeks. Post test values were taken after the treatment of 3 weeks.

Statistical analysis was performed using SPSS for Windows 10.0 (SPSS Inc.). Baseline differences between the treatment and control groups were compared using the 

on Shoulder Alignment, Pulmonary Function and Aerobic Capacity in Subjects with forward Shoulder Posture.

Mann-Whitney test for continuous variables as appropriate. The within-group differences were investigated using paired t-test for parametric data. An alpha level of 0.05 was used to test for statistical significance and all tests were two-tailed. When the pre and post means were compared using paired t test, statistically significant difference was obtained for all the outcome measures. Subjects showed significant improvement in scapular index right $(t=5.967)$, scapular index left ( $t=10.494)$, chest expansion ( $t=8.162)$, incentive spirometer $(\mathrm{t}=4.05)$, and 6 - minute walk test $(\mathrm{t}=2.785)$.

\section{RESULTS}

30 subjects who fulfilled the inclusion criteria were included in the study Paired t-test was used to compare the pre and post- test means. There were 3 drop Outs, following in which, data of 27 subjects were considered for data analysis. The characteristics of the subjects at baseline were normally distributed and are presented in Table 1.

Mean difference between pre- test and post- test values were $0.7(\mathrm{~cm})$ for scapular index right, $0.68(\mathrm{~cm})$ for scapular index left, $0.59(\mathrm{~cm})$ for upper chest expansion, 1.21 (secs) for inspiratory hold time using incentive spirometry and $6.79(\mathrm{~m})$ for aerobic capacity

When the pre and post means were compared using paired t test, statistically significant difference was proved for all the outcome measures. (Table 2) Subjects showed significant improvement in scapular index right (5.967, p<0.05), scapular index left (10.494, $p<0.05)$, chest expansion $(8.162, p<0.05)$, incentive spirometer $(4.05, p<0.05)$, and 6 -minute walk test $(2.785, p<0.05)$. The results demonstrated that scapular retraction exercise showed improvement in the values of scapular index, chest expansion, inspiratory hold time and 6- minute walk test.

Table 1: general characteristics of subjects at baseline.

\begin{tabular}{lc}
\multicolumn{1}{c}{ Gender (male/female) } & $\mathbf{1 2 - 1 5}$ \\
\hline Age (years) & 19.57 \\
\hline Height $(\mathbf{c m})$ & 165.9 \\
Weight $(\mathbf{k g})$ & 59.1 \\
Height $(\mathrm{cm})$ & 165.9 \\
Body mass index $\left(\mathrm{kg} / \mathrm{m}^{2}\right)$ & 20.1 \\
\hline
\end{tabular}

$n=27$, all values expressed in mean in mean, gender in ratio, Baseline homogeneity analysed using Kolmogorov - Smirnov test
Table 2: pre and post values of outcome measures.

\begin{tabular}{cccc}
\hline & PRE TEST & POST TEST & p value \\
\hline SI - R & $4.3 \pm 1.11$ & $3.6 \pm 0.79$ & $<0.05$ \\
SI - L & $4.47 \pm 0.96$ & $3.786 \pm 0.93$ & $<0.05$ \\
CE & $1.48 \pm 0.34$ & $2.07 \pm 0.18$ & $<0.05$ \\
IHT & $0.86 \pm 1.16$ & $2.07 \pm 1.54$ & 0.165 \\
6 MWT & $557.5 \pm 28.33$ & $564.29 \pm 27.09$ & 0.033 \\
\hline
\end{tabular}

Values are expressed in mean $\pm S D$, level of significance $<0.05$, data analysed using paired t test

SI-R - scapular index - right; SI-L - scapular index left; CE - chest expansion, IHT - inspiratory hold time. 6 MWT 6 minute walk test

\section{DISCUSSION}

This single group experimental study was done to evaluate the effect of scapular retraction exercises on shoulder alignment, pulmonary function and aerobic capacity in subjects with FSP. 27 subjects with FSP underwent a scapular retraction exercise for a period of 3 weeks. Values of scapular index, inspiratory hold time using incentive spirometry, chest expansion and 6 minute walk test was measured before and after the exercise program. The study found a strong evidence that scapular retraction exercises showed significant differences in the values of scapular index, inspiratory hold time, chest expansion and 6 minute walk test.

Exercise of scapular retraction muscle strengthening is proved to produce faster effects as a type of FSP intervention when compared to mere pectoralis stretching exercise. It is expected that therapeutic effect can be improved and the period can be shortened when strength exercise for forward shoulder posture is applied as a therapeutic intervention [13].

All the muscles connecting to scapula contribute to its optimal alignment. In Forward shoulder posture, dominance of Rhomboids and Levator scapulae activity leads to the downward rotation and anterior tilt of scapula, therefore placing the acromion process more anteriorly. Scapular retraction exercises mainly focus on strengthening muscles like Serratus anterior, Upper and Lower Trapezius, which are the main muscles responsible for the upward rotation and posterior tilting of scapula. Lynch $S$ S et al, suggest that FSP was reduced by strengthening of posterior shoulder muscles 
[14-23]. Strengthening these retractors pulls the scapula backwards and rotate it upwards, which in turn places the acromion process more posteriorly. This is evident from the change in the values of scapular index which is the distance between acromion process to the lying surface. The values were reduced significantly in subjects with forward shoulder and resulted in improving the alignment of shoulder [19].

When FSP is maintained for prolonged periods, it causes the shortening of the anterior shoulder girdle muscles and places humerus in internal rotation. This leads to shortening of pectoralis major and minor, and the intercostalis muscle which in turn increases muscle tension around the chest wall leading to reduction in thoracic range of motion [16]. Researchers have observed the link between forward head, forward shoulder, and thoracic kyphotic posture in their studies. Thoracis kyphosis is always a added reason for decreased chest wall movement [11]. Also, weakness of middle and lower trapezius reduces the ability to raise and expand the chest and alters the inspiratory mechanics [15]. Imbalance in these musculature due to weakness and shortening changes the articular movement available for breathing and influences the lung compliance [18]. Diab AA et al, suggested that the strengthening exercises of back muscles using elongation and elastic bands helps to stretch anterior musculature [14], which in turn helps to reduce the tension around chest wall and improves chest thoracic range of motion. Meanwhile strengthening of the posterior musculature improves the ability of the chest to expand.

Diaphragm, which is the major muscle of inspiration, has several attachments to ribcage and associated bony structures. Changes in the position of these structures alters the proper functioning of the diaphragm. Normally it contracts and relaxes in order to maintain proper breathing mechanics and also contributes significantly to spine stability and rib cage movement. If any restriction of the ribcage occurs during slouched position, it limits the mobility of the diaphragm which subsequently induces alteration in breathing mechanics [19]. This contributes to reduction in lung volumes and capacities and limits the ability to maximise the lung capacity. Increase in values of upper chest expansion and changes in inspiratory hold time measured using incentive spirometry proves that scapular retraction exercises reverse the entire pathomechanics of breathing and helps to improve pulmonary functions.

Aerobic capacity refers to the functional capacity of cardiorespiratory system to provide oxygen to the circulating blood. It is directly proportional to the capacity of cardiorespiratory system to supply oxygen. Decreased lung ventilation is always associated with decreased maximum $\mathrm{O} 2$ consumption [20-22] and studies states that impairment of pulmonary function leads to fatiguability and reduction in exercise tolerance [21]. Therefore, improvements in the lung volumes and capacities may be the possible reason responsible for the changes in values of aerobic capacity [20].

Hence it can be concluded that the scapular retraction exercise has a positive effect on improving the shoulder alignment, pulmonary function, and aerobic capacity in subjects with FSP.

\section{CONCLUSION}

Results of the study states that scapular index, chest expansion, inspiratory hold time and 6 minute walk test reveals that scapular retraction exercises has a positive impact on improving shoulder alignment, pulmonary function, and aerobic capacity. It can be concluded that scapular retraction exercises is effective in improving shoulder alignment, pulmonary function, and aerobic capacity in subjects with FSP. Hence, scapular retraction exercises can be included in exercise programs for improving forward shoulder posture
ABBRAVATIONS
FSP- Forward Shoulder Posture
FEV1- Forced Expiratory Volume in First Second
FVC- Forced Vital Capacity
6MWT- Six Minute Walk Test
COPD-Chronic Obstuctive Pulmnary Disease
BMI- Body Mass Index

VO2MAX-Maximal Oxygen Consumption 
Reethu Elsa, Jesmi John. A, Mohammed Shafeeq KP, Sivani.U. A. Remya. N, Manju Unnikrishnan. Effect of Scapular Retraction Exercise on Shoulder Alignment, Pulmonary Function and Aerobic Capacity in Subjects with forward Shoulder Posture.

\section{ACKNOWLEDGEMENTS}

We thank our subjects who co-operated with us.

\section{Conflicts of interest: None}

\section{REFERENCES}

[1]. Yang $H, B a e ~ S$ : Effects of shortening of pectoralis minor muscle on muscle activity of trapezius and pectoralis major muscles. J Korean Soc of Integrative Medicine. 2013;1.4:85-92.

[2]. Raine S, Twomey LT. Head and shoulder posture variations in 160 asymptomatic women and men. Arch Phys Med Rehabil. 1997;78(11):1215-1223.

[3]. Griegel-Morris P, Larson K, Mueller-Klaus K, Oatis $C A$. Incidence of common postural abnormalities in the cervical shoulder, and thoracic regions and their association with pain in two age groups of healthy subjects. Phys Ther.1992 Jun; 72(6);42531.

[4]. Ghanbari A, Ghaffarinejad F, Mohammadi F, Khorrami M, Sobhani S. Effect of forward shoulder posture on pulmonary capacities of women. $\mathrm{Br} \mathrm{J}$ Sports Med. 2008;42(7):622-623.

[5]. Darius felix. Posture and Fitness (Part 1): Kyphosis (Rounded Shoulders)[Online]. Available from: https://www.nifs.org/blog/posture-and-fitnesskyphosis-rounded-shoulders [Accessed 10 June 2020].

[6]. Peterson DE, Blankenship KR, Robb JB, et al. Investigation of the validity and reliability of four objective techniques for measuring forward shoulder posture. J Orthop Sports Phys Ther.1997;25:3442.

[7]. Kisner, C, Colby , L.A. Therapeutic exercise: foundations and techniques. (4th ed.). Philadelphia: FA Davis Co; 2002;319-24.

[8]. Alaa S, Baiee HA. Impact of School Bag on Pulmonary Functions among Elementary School Children in Al-Hilla City-Iraq . Medical Journal of Babylon. 2016;12(4):1101 -1108.

[9]. S. Breslav, M. O. Segizbaeva, G. G. Isaev z. Does the Respiratory System Limit the Aerobic Working Capacity of Humans? Human Physiology. 2000;26(4): 481-487.

[10]. Lewis JS, Valentine RE. The pectoralis minor length test: a study of the intra-rater reliability and diagnostic accuracy in subjects with and without shoulder symptoms. BMC Musculoskeletal disord. 2007;8(1):64.

[11]. Singla D, Veqar Z. Association Between Forward Head, Rounded Shoulders, and Increased Thoracic Kyphosis: J Chiropr Med.2017 Sep; 16(3): 220-229.
[12]. Won-gyu Yoo. Comparison of the effects of pectoralis muscles stretching exercise and scapular retraction strengthening exercise on forward shoulder; J Phys Ther Sci. 2018 Apr;30(4):584-585.

[13]. Tae-Woon Kim, Da- In An, Hye- Yun Lee, Ho-Young Jeong, Dong- Hyung Kim. Effects of elastic band exercise on subjects with rounded shoulder posture and forward head posture: J Phys Ther Sci. 2016 Jun; 28(6): 1733-1737.

[14]. Diab AA, Moustafa IM: The efficacy of forward head correction on nerve root function and pain in cervical spondylotic radiculopathy: a randomized trial. Clin Rehabil, 2012;26:351-361.

[15]. Kendall FP, McCreary EK, Provance PG. Muscles: Testing and Function. $\left(4^{\text {th }}\right.$ ed). Baltimore: Williams and Wilkins publication; 1993:69-75.

[16].S, Veena Kirthika, Selvaraj Sudhakar, K Padmanabhan, K Ramanathan; Impact of upper crossed syndrome on pulmonary function among the recreational male players:A preliminary report. Saudi J Sports Med. 2018;18(2) :71-74.

[17]. J. Ackermann, N. O'Dwyer,and M.Halaki. The difference between standing and sitting in 3 seat inclinations on abdominal muscle activity and chest and abdominal expansion in woodwind and brass musicians, Front. Psychol.2006;87(4): 504-509.

[18]. F. Lin, S. Parthasarathy, S. J, Taylor, D.Pucci,R. WS .Hendrix, and M.Makhsous. Effect of different sitting postures on lung capacity, expiratory flow, and lumbar lordosis, Arch Phys Med Rehabil.2006 Apr;87(4):504-9.

[19]. A. Mihailova and I. Kaminska ;Lung volumes related to physical activity, physical fitness, aerobic capacity and body mass index in students. SHS Web of Conferences. 2016; 30

[20]. Lydick E, Zimmerman SI, Yawn B, Love B, Kleerek oper $M$, Ross $P$, et al. Development and validation of a discriminative quality of life questionnaire for osteoporosis. J Bone Miner Res 1997;12:456-63.

[21]. Komatsu WR, Barros Neto TL, Chacra AR, Dib SA. Aerobic exercise capacity and pulmonary function in athelets with and without type 1 diabetes. Diabetes Care.2010 Dec;33(12):2555-7.

[22]. Mohan V, Dzulkifi NHF, Justine M, Haron R, H LJ, Rathinam C. Intra rater reliability of chest expansion using cloth tape measure technique Bangladesh Journal of Medical Science, 2012; 11(4):307-311.

[23]. Lynch SS, Thigpen CA, Mihalik JP, et al, The effects of an exercise intervention on forward head and rounded shoulder postures in elite swimmers. $\mathrm{Br} J$ Sports Med, 2010;44:376-381.

How to cite this article: Reethu Elsa, Jesmi John. A, Mohammed Shafeeq KP, Sivani.U. A. Remya. N, Manju Unnikrishnan. Effect of Scapular Retraction Exercise on Shoulder Alignment, Pulmonary Function and Aerobic Capacity in Subjects with forward Shoulder Posture. Int J Physiother Res 2021;9(4):3944-3948. DOI: 10.16965/ijpr.2021.154 